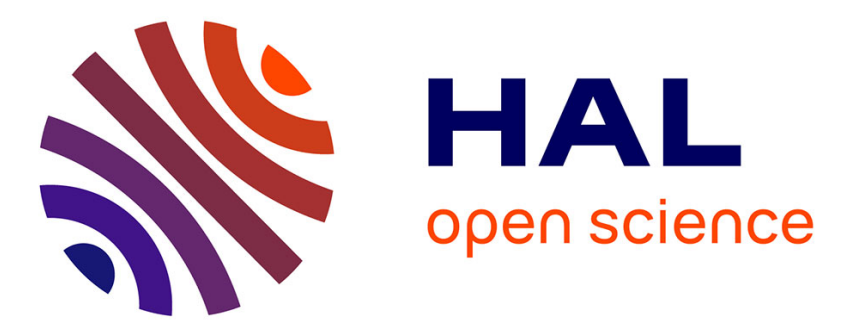

\title{
The Statistical Molecular Fragmentation model com- pared to experimental plasma induced hydrocarbon decays
}

Pierre Désesquelles, Stéphane Pasquiers, Nicole Blin-Simiand, Lionel Magne, Nguyen-Thi Van-Oanh, Sébastien Thomas, Dominik Domin

\section{To cite this version:}

Pierre Désesquelles, Stéphane Pasquiers, Nicole Blin-Simiand, Lionel Magne, Nguyen-Thi Van-Oanh, et al.. The Statistical Molecular Fragmentation model com- pared to experimental plasma induced hydrocarbon decays. Physical Chemistry Chemical Physics, 2020, 22 (14), pp.7586-7596. 10.1039/C9CP06958E . hal-02997248

\section{HAL Id: hal-02997248 \\ https://hal.science/hal-02997248}

Submitted on 10 Nov 2020

HAL is a multi-disciplinary open access archive for the deposit and dissemination of scientific research documents, whether they are published or not. The documents may come from teaching and research institutions in France or abroad, or from public or private research centers.
L'archive ouverte pluridisciplinaire HAL, est destinée au dépôt et à la diffusion de documents scientifiques de niveau recherche, publiés ou non, émanant des établissements d'enseignement et de recherche français ou étrangers, des laboratoires publics ou privés. 


\title{
The Statistical Molecular Fragmentation model com- pared to experimental plasma induced hydrocarbon decays.
}

\author{
Pierre Désesquelles ${ }^{a, b}$, Stéphane Pasquiers ${ }^{a}$, Nicole Blin-Simiand ${ }^{a}$, Lionel Magne ${ }^{a}$, \\ Nguyen-Thi Van-Oanh ${ }^{c}$, Sébastien Thomas ${ }^{a}$, and Dominik Domin ${ }^{* d, e}$
}

Received Date

Accepted Date

DOI: $00.0000 / x x x x x x x x x x$

\begin{abstract}
We compare the predictions of our recently developed statistical molecular fragmentation (SMF) model with experimental results from plasma induced hydrocarbon decay. The SMF model is an exactly solvable statistical model, capable to calculate the probabilities for all possible fragmentation channels as a function of the deposited excitation energy. The weights of the channels are calculated from the corresponding volume of the accessible phase space of the system, taking into account all relevant degeneracies, symmetries and density functions. An experiment designed to study the abatement of propene in $\mathrm{N}_{2}$ using a photo-triggered discharge producing a homogeneous plasma at sub-atmospheric pressure was also performed. Using a OD model that simulates the complex chemical kinetics in the plasma, it was possible to assess the percentages of the original parent hydrocarbon's fragmentation channels based on the detected species. These results were compared to those obtained from the SMF model. Previous plasma induced hydrocarbon fragmentation experiments for ethene, ethane and propane, where also compared to the predictions of the SMF model. For energies below that of metastable dinitrogen (i.e. below $6.17 \mathrm{eV}$ and $8.4 \mathrm{eV}$ ), the SMF model and the experimental fragmentation channels coincide. This study allows one to draw conclusions both on the range of excitation energies transferred to the parent hydrocarbon molecules during plasma discharge and on the probability of the dynamical coupling of two $\mathrm{H}$ atoms from neighbouring carbon atoms to form $\mathrm{H}_{2}$ molecules.
\end{abstract}

\section{Introduction}

Statistical physics models have been used since the beginning of physical chemistry to describe the fragmentation of isolated molecules ${ }^{11+3}$. Unlike for the more commonly used molecular dynamics models, one does not need to simulate the evolution of the whole system from the initial excitation to the complete separation of the fragments. The results from the SMF model are the probabilities of all the fragmentation channels. This information is sufficient in many circumstances, notably when comparing with experimental observations. Moreover, isomerization pro-

\footnotetext{
${ }^{a}$ Université Paris-Saclay, CNRS, Laboratoire de physique des gaz et des plasmas, 91405 , Orsay, France.

${ }^{b}$ Huazhong, Univ Sci \& Technol, Sch Energy \& Power Engn, Dept Nucl Engn \& Technol, Wuhan 430074, Hubei, Peoples R China.

' Université Paris-Saclay, CNRS, Laboratoire de Chimie Physique, 91405, Orsay, France.

${ }^{d}$ Faculty of Biotechnology, Chemistry and Environmental Engineering, PHENIKAA University, Hanoi 12116, Vietnam

e PHENIKAA Institute for Advanced Study (PIAS), PHENIKAA University, Hanoi 12116, Vietnam ;E-mail: dominik.domin@phenikaa-uni.edu.vn
}

cesses like rearrangements (atoms or bonds) or re-combination reaction (e.g. absorption of a neighbouring hydrogen atom to produce a $\mathrm{H}_{2}$ or a $\mathrm{CH}_{4}$ fragment) can be readily implemented in the SMF model.

Molecules upon excitation often undergo ultrafast decay back to the electronic ground state through various non-radiative processes such as internal conversion ${ }^{45}$ or intersystem crossing 6 The molecules are then often in very excited vibrational states of their ground electronic states, which after a significant longer time may lead to their dissociation. The SMF model is well adapted for treating such excited molecules.

Hydrocarbons pollutants from human activities, such as transportation and pollution from chemical industries, are detected at virtually all urban background sites ${ }^{[}$. Among these molecules, propene $\left(\mathrm{C}_{3} \mathrm{H}_{6}\right)$ is a natural fuel, and a reagent for the formation of polypropene in industry. As far as depollution processes are concerned, propene has become since the 1990's a relevant compound for studying the conversion of unburned unsaturated hydrocarbons contained in car engine exhaust by non-thermal plas- 
mas 910 . It has been shown to play an important role in the kinetic chain reaction leading to the removal of nitrogen oxide $\mathrm{e}^{11 \mid 12}$. Therefore, the kinetics of propene in plasmas produced in atmospheric gases $\left(\mathrm{N}_{2}, \mathrm{O}_{2}, \mathrm{H}_{2} \mathrm{O}\right)$ deserves to be studied, in particular in lean oxygen mixtures for which oxidation processes by radicals (e.g., ${ }^{\bullet} \mathrm{OH}$ ) may play less of a role than dissociation caused by collisions with excited states of the nitrogen molecule.

Propene also belongs to the list of known interstellar and circumstellar molecules 13 . Furthermore, it was recently detected in Titan's stratosphere 14 . Therefore, it plays a role in the complex chemistry that occurs in space, where it is the result of the competition between growth due to constructive reactions and fragmentation, mostly due to the photon bath $[15[16$.

In this paper, we compare the prediction of the SMF model to our experimental results obtained by exciting propene (and several other small hydrocarbons: ethene, ethane and propane) using a plasma.

\section{Plasma abatement of propene experiment}

A first step towards the understanding of the kinetics in air/hydrocarbon mixtures is the investigation of the decomposition mechanisms of a hydrocarbon molecule in the nitrogen plasma. Results were obtained for the $\mathrm{N}_{2}$ /propene mixture at subatmospheric pressure $\frac{17}{}$, using a photo-triggered discharge producing a homogeneous plasma ${ }^{18}$. The physics of such a discharge is known and the use of OD-models, in conjunction with the results of the measurements, allows studying complex plasma kinetics without a simplifying hypothesis about the electrical energy deposition in the inter-electrode space. Experimental protocols and the developed models have been previously described 19.21 . The operating principle of the photo-triggered discharge reactor is as follows. Two metallic electrodes are directly connected to an energy storage unit charged up to a voltage $V_{0}$, and the breakdown of the gas is achieved through UV-ionization of the gas mixture. Then, the electric field between the electrodes decreases and the discharge current pulse develops, the field dropping to zero at the end. The low inductance of the electrical circuit allows one to achieve a short discharge current pulse of $60 \mathrm{~ns}$, during which the plasma reactivity proceeds (electron collisions on molecules to produce excited state atoms, radicals, ions and various reactions between these species). In a closed loop with a total volume (9 L) much higher than the volume in which the discharge occurs $\left(50 \mathrm{~cm}^{3}\right)$, a gas compressor is used to produce a gas flow through the inter-electrode space and the pulse repetition frequency is chosen such that the discharge volume is renewed between two consecutive pulses. After each current pulse follows a long postdischarge period, during which the chemical reactivity between neutral species develops. The original organic molecules progressively disappear whereas stable by-products accumulate as the gas mixture undergoes an increasing number of current pulses, each depositing equal quantities of electrical energy. Concentrations of molecules are measured in the total volume as a function of the number of pulses, using various chromatography or mass spectrometry techniques. A primary model describes, selfconsistently, the electrical energy deposition in the inter-electrode space and the non-equilibrium reactivity of the plasma, and a second model determines, with some kinetic approximations, the gradual modification of the gas mixture as it is subjected to more and more pulses. Through the use of such coupled experimental and modeling tools, we have found over the past ten years that the first metastable excited state of nitrogen molecule, $\mathrm{A}^{3} \Sigma_{\mathrm{u}}^{+}$ (excitation threshold at $6.17 \mathrm{eV}$ ), as well as the group of singlets a' ${ }^{1} \Sigma_{\mathrm{u}}^{-}$, a ${ }^{1} \Pi_{\mathrm{g}}$ and $\mathrm{w}^{1} \Delta_{\mathrm{u}}$ (threshold at $8.4 \mathrm{eV}$ ), can play an important role in the degradation of some hydrocarbons or oxygenated volatile organic compounds $19-23$. Quenching collisions of these electronically excited states of nitrogen, lead mostly to the dissociation of the organic molecules. This has been observed for $\mathrm{N}_{2}^{*}\left(\mathrm{~A}^{3} \Sigma_{\mathrm{u}}^{+}\right)$in the literature, and it has been measured to be the dominant channel for numerous compounds 24 . For propene, the following quenching reactions ${ }^{17}$ were first proposed:

$$
\begin{array}{lll}
\mathrm{N}_{2}^{*}\left(\mathrm{~A}^{3} \Sigma_{\mathrm{u}}^{+}\right)+\mathrm{C}_{3} \mathrm{H}_{6} & \longrightarrow \mathrm{N}_{2}+\mathrm{CH}_{3} \mathrm{CHCH}_{2}^{*} \\
\mathrm{~N}_{2}^{*}\left(\mathrm{~A}^{3} \Sigma_{\mathrm{u}}^{+}\right)+\mathrm{C}_{3} \mathrm{H}_{6} & \longrightarrow \mathrm{N}_{2}+\mathrm{CH}_{2} \mathrm{CHCH}_{2}+\mathrm{H} \\
\mathrm{N}_{2}^{*}\left(\mathrm{~A}^{3} \Sigma_{\mathrm{u}}^{+}\right)+\mathrm{C}_{3} \mathrm{H}_{6} & \longrightarrow \mathrm{N}_{2}+\mathrm{CH}_{2} \mathrm{CH}+\mathrm{CH}_{3}
\end{array}
$$

with $\mathrm{CH}_{3} \mathrm{CHCH}_{2}^{*}$ in a radiative excited state (non-dissociative quenching) and similar reactions for singlet states; estimated branching ratios were $45 \%$ for (1) and $27.5 \%$ both for (2) and (3). However, uncertainties remained about the exit routes for the two dissociation processes (2) and (3). Measurements of the $\mathrm{H}_{2}$ concentration produced in the $\mathrm{N}_{2} / \mathrm{C}_{3} \mathrm{H}_{6}$ mixture gave some answers to this issue $\frac{23}{}$, leading to the following alternative to (3):

$$
\mathrm{N}_{2}^{*}+\mathrm{C}_{3} \mathrm{H}_{6} \longrightarrow \mathrm{N}_{2}+\text { product }+\mathrm{H}_{2}
$$

where $\mathrm{N}_{2}^{*}$ stands for a nitrogen molecule that is excited to either $\mathrm{A}^{3} \Sigma_{\mathrm{u}}^{+}$or one of the singlet states levels. The branching ratios changed to $45 \%$ for (1), $50 \%$ for (2) and $5 \%$ for (4), but the kinetic coefficients remained unchanged, i.e. $k=2.810^{-10} \mathrm{~cm}^{3} \mathrm{~s}^{-1}$ for all $\mathrm{N}_{2}^{* 24}$.

In figure 1 the propene concentration is measured in the total volume of the experiment as a function of the number of current pulses, compared to predictions of the discharge and kinetic models (solid lines), for two values of the initial concentration, $500 \mathrm{ppm}$ and $1000 \mathrm{ppm}$ (other parameters are given in the figure caption). The results emphasize that reactions (2) and (4) explain quite well the removal of the hydrocarbon molecule, together with other processes which are taken into account in our kinetic scheme, the most important being:

$$
\begin{array}{lll}
\mathrm{N}+\mathrm{C}_{3} \mathrm{H}_{6} & \longrightarrow \mathrm{HCN}+\mathrm{C}_{2} \mathrm{H}_{5} \\
\mathrm{H}+\mathrm{C}_{3} \mathrm{H}_{6} & \longrightarrow \text { iso }-\mathrm{C}_{3} \mathrm{H}_{7}
\end{array}
$$

The OD kinetic model used in the analysis of the experimental data also takes into account that the recombination of radicals also occurs, causing the reformation of the original molecule:

$$
\begin{aligned}
\mathrm{H}+\mathrm{CH}_{2} \mathrm{CHCH}_{2} & \longrightarrow \mathrm{C}_{3} \mathrm{H}_{6} \\
\mathrm{CH}_{3}+\mathrm{C}_{2} \mathrm{H}_{3} & \longrightarrow \mathrm{C}_{3} \mathrm{H}_{6}
\end{aligned}
$$




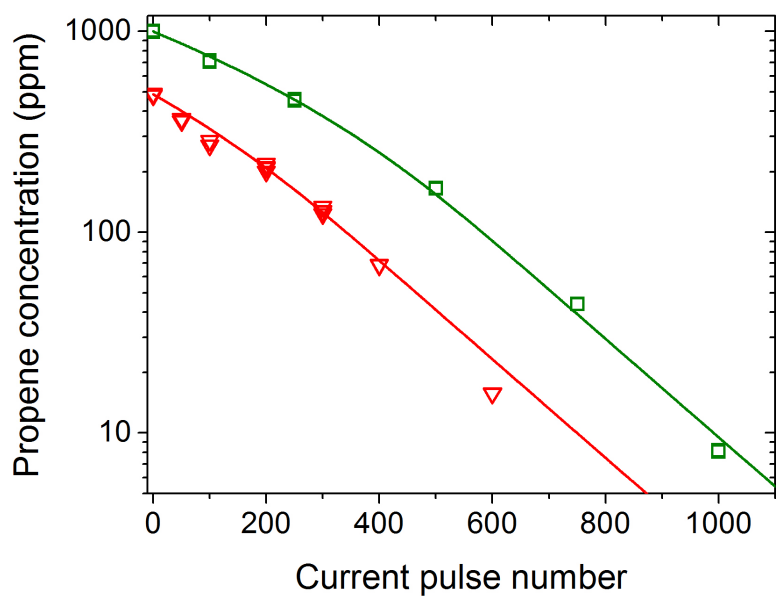

Fig. 1 (Color online) Propene concentration in the experimental reactor $(9 \mathrm{~L})$ including a photo-triggered discharge $\left(50 \mathrm{~cm}^{3}\right)$. Total pressure of the $\mathrm{N}_{2} / \mathrm{C}_{3} \mathrm{H}_{6}$ mixture: 0.46 bar. Deposited energy in the plasma per current pulse: $4.6 \mathrm{~J}(92 \mathrm{~J} / \mathrm{L})$. Squares are the measurements for an initial concentration of $1000 \mathrm{ppm}$ and triangles are for an initial concentration of $500 \mathrm{ppm}$. Lines are for model predictions.

where the species involved are coming either from (2) or from the dissociation of by-products and the chemical reactivity of the gas mixture energized by the pulsed discharge. The detected molecular by-products are numerous in the experiment, essentially the hydrogen molecule and light hydrocarbons: $\mathrm{CH}_{4}, \mathrm{C}_{2} \mathrm{H}_{2}, \mathrm{C}_{2} \mathrm{H}_{4}$, $\mathrm{C}_{2} \mathrm{H}_{6}$, and $\mathrm{C}_{3} \mathrm{H}_{8}$, all of them also predicted by the kinetic scheme.

Reaction (4) plays an important role in the production of $\mathrm{H}_{2}$. It is interesting to note that, previously in the literature, a molecular elimination process was experimentally demonstrated by $\mathrm{H}$. Umemoto ${ }^{31}$ showing that $\mathrm{H}$ and $\mathrm{H}_{2}$ are both produced following the collision of $\mathrm{N}_{2}^{*}\left(\mathrm{~A}^{3} \Sigma_{\mathrm{u}}^{+}\right)$with $\mathrm{C}_{2} \mathrm{H}_{4}$. In the case of conversion of propene during the photo-triggered discharge, $\mathrm{H}_{2}$ can come directly from the quenching of $\mathrm{N}_{2}^{*}$ states but also from some chemical reactions, most importantly:

$$
\begin{aligned}
\mathrm{H}+\mathrm{CH}_{2} \mathrm{CHCH}_{2} & \longrightarrow \mathrm{H}_{2}+\mathrm{CH}_{2} \mathrm{CCH}_{2} \\
\mathrm{H}+\mathrm{H}_{2} \mathrm{CN} & \longrightarrow \mathrm{H}_{2}+\mathrm{HCN} \\
\mathrm{H}+\mathrm{C}_{2} \mathrm{H}_{3} & \longrightarrow \mathrm{H}_{2}+\mathrm{C}_{2} \mathrm{H}_{2}
\end{aligned}
$$

Moreover, if the production of $\mathrm{H}_{2}$ is assumed to be a three step process involving the sequential emission of two hydrogen atoms followed by $\mathrm{H}_{2}$ formation, then the hydrocarbon product in (4) would be preferentially 1,2-Propadiene, $\mathrm{CH}_{2} \mathrm{CCH}_{2}$. Indeed, in this case, the bond dissociation energy for removing one of the hydrogen atoms from the methyl group is $3.7 \mathrm{eV}$. The corresponding bond dissociation energy for the removal of an hydrogen atom from the vinyl group is $4.7 \mathrm{eV}$. In the second step, the other hydrogen atom constituting $\mathrm{H}_{2}$ is provided by the central carbon. When the reaction is seen as a simultaneous dynamical process, the global binding energy for $\mathrm{H}_{2}$ emission is slightly lower for $\mathrm{CH}_{3} \mathrm{CCH}(1.70 \mathrm{eV})$ than for $\mathrm{CH}_{2} \mathrm{CCH}_{2}(1.73 \mathrm{eV})$. The experiment did not allow to make a conclusion since neither 1,2-Propadiene nor 1-Propyne were clearly identified in the mixture treated by the discharge. Future work will attempt to resolve experimentally this issue.

The analysis of the proceeding experimental measurements were performed by conjecturing the possible fragments resulting from the initial fragmentation phase, then tuning their proportions so that the results from the two OD kinetic models previously described correspond to the measured final molecular concentrations. In the next section, we introduce the SMF model that models the fragmentation of the parent molecules independently of experimental data.

\section{SMF: Statistical Molecular Fragmentation}

\subsection{Introduction}

$\mathrm{SMF}^{32} 33$ is an exactly solvable statistical model that has been developed by us. It is capable of calculating the probabilities for all possible fragmentation channels (this amounts to 223 in the case of propene) as a function of deposited energy. Since interaction times for electron collisions and for quenching reactions, are much shorter than the time required for the molecular nuclei to move, a considerable portion of the molecules are found in the electronic excited states. This excited energy will be redistributed among the molecule's vibrational degrees of freedom after the excitation has occurred via the internal conversion processes. Consequently, one can treat the parent molecule decay as a post-collisional process that is mainly controlled by the amount of deposited excitation energy 34 . The usual way of studying such excited molecule dissociation is through the simulation of the time evolution of the many-body system. The molecular systems are prepared to possess a desired quantum vibrational internal energy and then their dynamics evolve classically with time 35.39 . Several thousands (or more) trajectories have to be performed in order to determine the branching ratios of the reaction. Running direct "on the fly" ab initio molecular dynamics for studying the reaction processes is highly time consuming. Therefore, some acceleration techniques have been developed: for small systems one often pre-builds the potential energy surface from $a b$ initio calculations 35136 , for larger systems one runs molecular dynamics simulations using approximate quantum chemical methods such as DFTB 40 . Nevertheless, running the large number of trajectories necessary to study extensively the fragmentation channels of large systems or systems that result in a large number of fragments, over a large range of excitation energies, is frequently too costly computationally. On the other hand, when the ergodic hypothesis is valid, that is when the final state resulting from the time evolution is mainly governed by the structure of the accessible $N$-body phase space, microcanonical thermodynamics, as implemented in SMF, is able to predict the final state probabilities. The required computational effort in this case is considerably less. This comes at the cost of losing the kinetic information about the fragmentation paths, since statistical models only give the final thermodynamic results. In the case of SMF, it is the probabilities of the fragmentation channels as a function of the excitation energy. 
In the subsequent section, we describe the main features of the SMF model, then we present its prediction concerning fragmentation channel and species production probabilities for the fragmentation of propene. Since the model depends on structural data obtained from quantum chemistry methods, the influence of the chosen method will be assessed. Subsequently, these theoretical results will be compared to the experimental data introduced in the previous section.

\subsection{Model description}

The SMF model has no empirically tunable parameters that need to be adjusted to reproduce experimental data. It depends only on parameters describing the shape, energies and quantum numbers (see Appendix table 2) of the parent molecule as well as that of the fragment species (molecules, atoms and radicals). These parameters need to been obtained from quantum chemistry models.

The statistical model considers the microcanonical ensemble in which the accessible phase space volume is restricted by the conservation laws on atoms, total energy, total linear momentum and total angular momentum. The physical observables are evaluated as weighted averages over the phase space. The statistical weight of a fragmentation channel is equal to the number of physically accessible states and is determined by the structural features of the channel fragments only. Then, the probabilities of the individual fragmentation channels can be calculated since the weights are known for all channels. In addition to the degeneracies due to the quantum numbers and the shape symmetries of the fragments and the combinatorial factors due to equivalent ways of breaking the parent molecule's bonds, the statistical weights are proportional to the available energy (energy remaining after removal of the channel dissociation energy) convolution among total kinetic and fragment vibrational degrees of freedom. The corresponding densities of states are proportional to, respectively, $\rho\left(E_{\text {kin }}\right) \propto E_{\text {kin }}^{\alpha-1} \pi^{\alpha} / \Gamma(\alpha)$, where $2 \alpha$ is the number of kinetic degrees of freedom and $\Gamma$ is Euler's gamma function, and $\rho\left(E_{j}^{*}\right)=E_{j}^{* f_{v j}-1} /\left(\Gamma\left(f_{v_{j}}\right)\left(h \bar{v}_{j}\right)^{f_{v_{j}}}\right)$, where $f_{v}$ is the number of vibrational degrees of freedom, $E^{*}$ is the fragment vibrational energy and $\bar{v}$ is the geometrical average of its vibrational modes ( calculated using the harmonic oscillator approximation).

SMF considers only one step processes for the fragmentation of the isolated parent molecule. It does not treat species lifetimes nor reactions with the plasma gas (these post-fragmentation processes are accounted for by the two kinetic models described in Section 2). The SMF model includes, on demand, rearrangement and re-combinations processes that could occur during the fragmentation process. These processes include $\mathrm{H}_{2}$ pairing from isolated hydrogen atoms released from neighboring carbon atoms, formation of $\mathrm{CH}_{4}$ (resp. $\mathrm{CH}_{3}, \mathrm{CH}_{2}$ ) from an isolated $\mathrm{CH}_{3}$ (resp. $\mathrm{CH}_{2}, \mathrm{CH}$ ) and the closure of three carbon rings (noted with a $\Delta$ in the tables and figures).

Significant effort has been invested in the quality of the convolution algorithm since it is the central part of the SMF calculation that takes the longest time (excluding time needed to acquire quantum chemistry data). We have shown that the convolution expression could be rewritten as a function of an incomplete multivariate Beta function so that part of the convolution can be precalculated. As a consequence, for propene the fragmentation part of the code takes less that 5 minutes on a single $2.3 \mathrm{GHz}$ Intel Core i9 processor core. Consequently, SMF can treat much larger systems. For example, it was used to study the fragmentation of metronidazole ${ }^{33}$ and we are presently working on the fluorene cation and on a resin $\mathrm{SO}_{3} \mathrm{C}_{18} \mathrm{H}_{22}$.

\subsection{Results}

The evolution, as a function of the parent (propene) molecule's excitation energy, of the fragmentation channel weights given by SMF is presented in figure 2. The structural and energetic properties of the species were obtained using the Gaussian-3 composite method (G3) (table 2). The same molecular parameters are used in figures 2 through 5 . The weights of the channels with fragment species differing only by their spin multiplicities, have been summed together. All fragmentation channel weights are monotonically increasing with excitation energy when it exceeds the threshold dissociation energy. This is due to the fact that, as the available energy increases, the accessible phase space volume increases. Up to $3.85 \mathrm{eV}$, the propene molecule absorbs vibrational energy while remaining stable. The first bond that breaks corresponds to the emission of an hydrogen atom from the $\mathrm{CH}_{3}$ group. If the recombination of hydrogen atoms into $\mathrm{H}_{2}$ is enabled in SMF (see appendix figure 11), then the first two fragmentation channels are: $\mathrm{CH}_{3} \mathrm{CCH}$ (propyne) $+\mathrm{H}_{2}$ and $\mathrm{CH}_{2} \mathrm{CCH}_{2}$ (propadiene) $+\mathrm{H}_{2}$ with a threshold energy of about $1.8 \mathrm{eV}$. A more complete description regarding the effect of rearrangement can be found in the appendix.

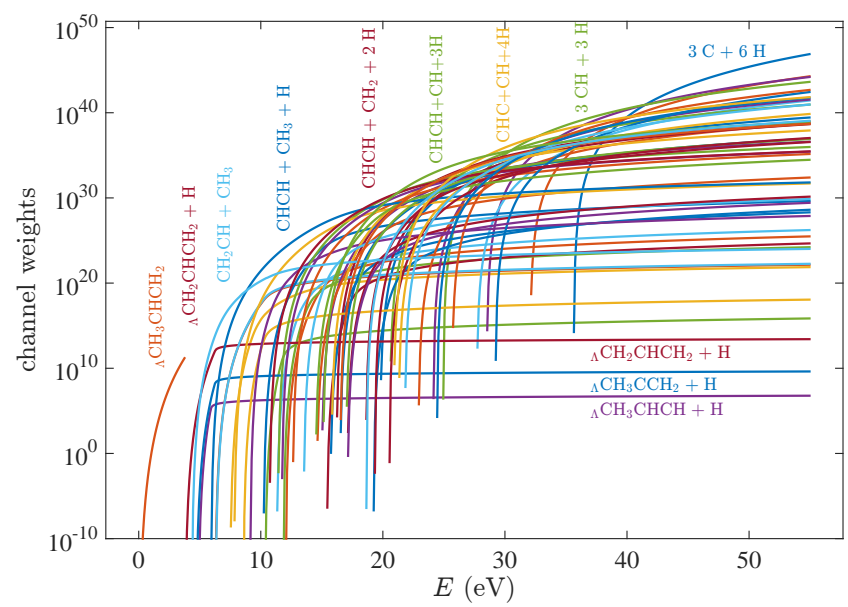

Fig. 2 (Color online) Fragmentation channel weights as a function of the parent (propene) molecule's excitation energy.

Normalizing the fragmentation channel weights by the total weight gives the channel probabilities shown in figure 3 Only a few channels have probabilities over 0.1. The first fragmentation channel (H emission) is dominant in a narrow energy range, 3.9 to $5.2 \mathrm{eV}$. The next bond to be broken is the $\mathrm{CH}_{3}-\mathrm{CH}$ bond, 
the corresponding fragmentation yield is dominant up to $8.8 \mathrm{eV}$. It is interesting to note that, considering the dissociation energies, the next two fragmentation channels are hydrogen emission from the central carbon and from the $\mathrm{CH}_{2}$ group (the two lower dark blue and violet curves in figure 2). However, these channels remain an ultra-minority (weights less than $10^{10}$, probabilities less than $310^{-6}$ ) due to the fact that, unlike $\mathrm{CH}_{3}, \mathrm{H}$ atoms can not accommodate vibrational excitation energy. Therefore, the energy convolution only includes total kinetic energy and $\mathrm{C}_{3} \mathrm{H}_{5}$ excitation energy. On the other hand, $\mathrm{CH}_{3}$ being relatively stable (dissociation energy of $4.9 \mathrm{eV}$ ), it appears in all the dominant channels from 5.2 up to $22 \mathrm{eV}$. In the intermediate energy range, several channels are in competition. At high excitation energy, over $48 \mathrm{eV}$, the system is dissociated into individual atoms.

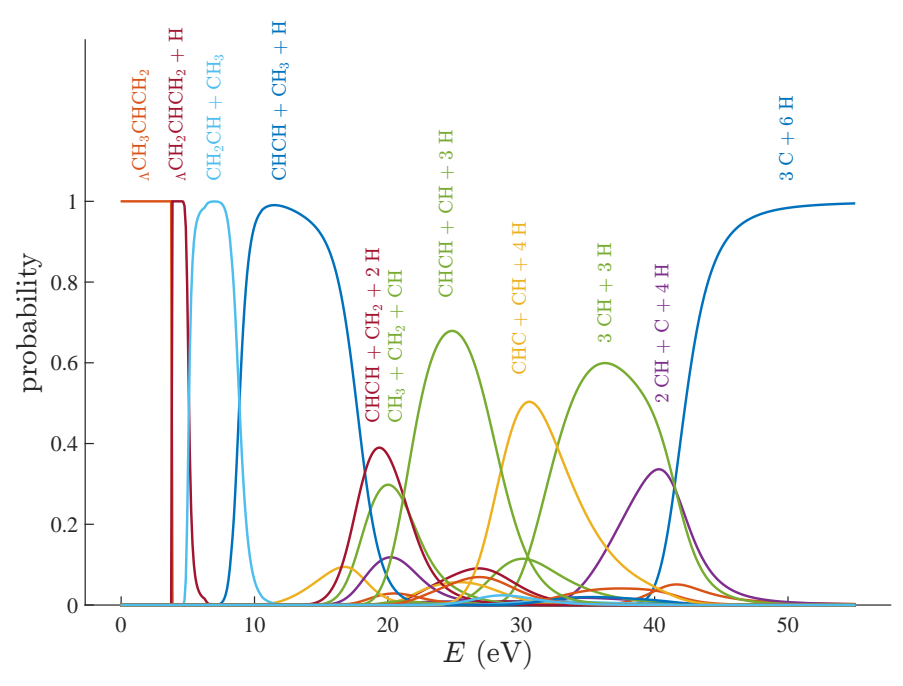

Fig. 3 (Color online) Fragmentation channel probabilities as a function of the propene molecule excitation energy. The channel colors are the same as in the previous figure.

As in most experimental set-ups, the correlation between the fragments belonging to the decay of the same parent molecule is lost in the case of plasma experiments. Only the proportions of the primary (formed during the fragmentation process) molecules can be deduced from experiment as explained in Section 2. The average number of primary molecules per propene fragmentation, are shown in figure 4. Only a dozen species have sizable probabilities. It is interesting to note that in the range $6-8 \mathrm{eV}$, that is well above its threshold of $3.85 \mathrm{eV}$, the hydrogen atom vanishes. If hydrogen recombination is systematically allowed, then the probabilities of $\mathrm{H}_{2}$ is important in the ranges $1.75-45 \mathrm{eV}$. Moreover, as seen in Appendix figure 11. $\mathrm{H}_{2}$ recombination also greatly enhances the probabilities of some three carbon species that are not visible in figure 4. $\mathrm{CH}_{3} \mathrm{CCH}, \mathrm{CH}_{2} \mathrm{CCH}_{2}$ (see discussion comparing to experimental results in Section 4), $\mathrm{CH}_{2} \mathrm{CCH}$, $\mathrm{CHCCH}$ and CCC. At higher excitation energies, the influence of $\mathrm{H}_{2}$ is much less important.

From the channel probabilities, one can deduce the distribution of the number of fragments (fragment multiplicity) as a function

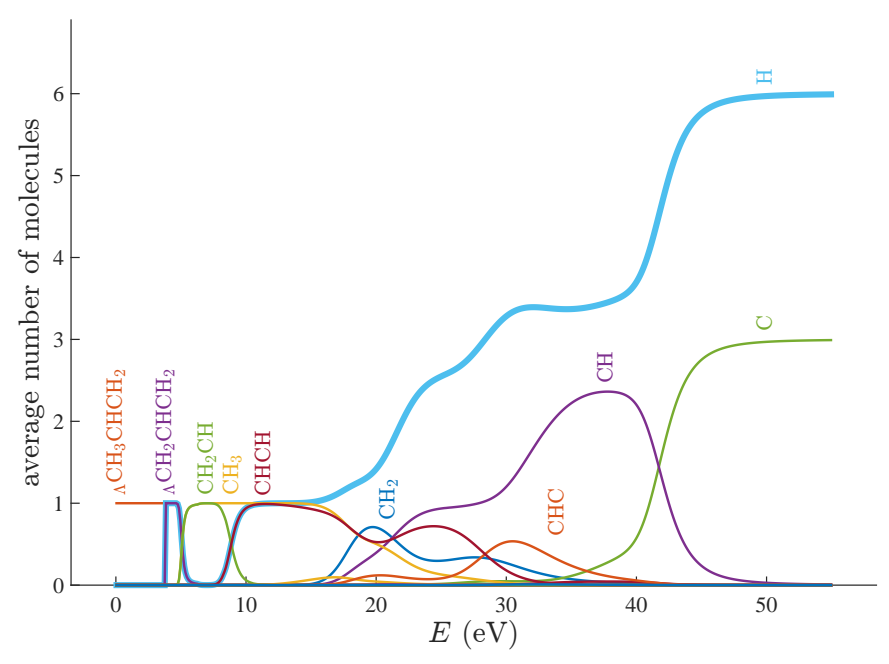

Fig. 4 (Color online) Fragment average numbers as a function of the propene molecule's excitation energy. The channel colors are the same as in the two previous figures.

of the excitation energy. In figure 5 the surfaces of the circles are proportional to the channel probability (the meaning of the channel colors is the same as in figure 3). As can be seen, the evolution of the average fragment multiplicity as a function of the excitation energy is nearly linear. In that respect, molecular fragmentation behaves like the fragmentation of other physical and mathematical systems such as atomic nuclei $\frac{41 \mid 42}{}$, atomic clusters ${ }^{43}$ and even random graphs 44 .

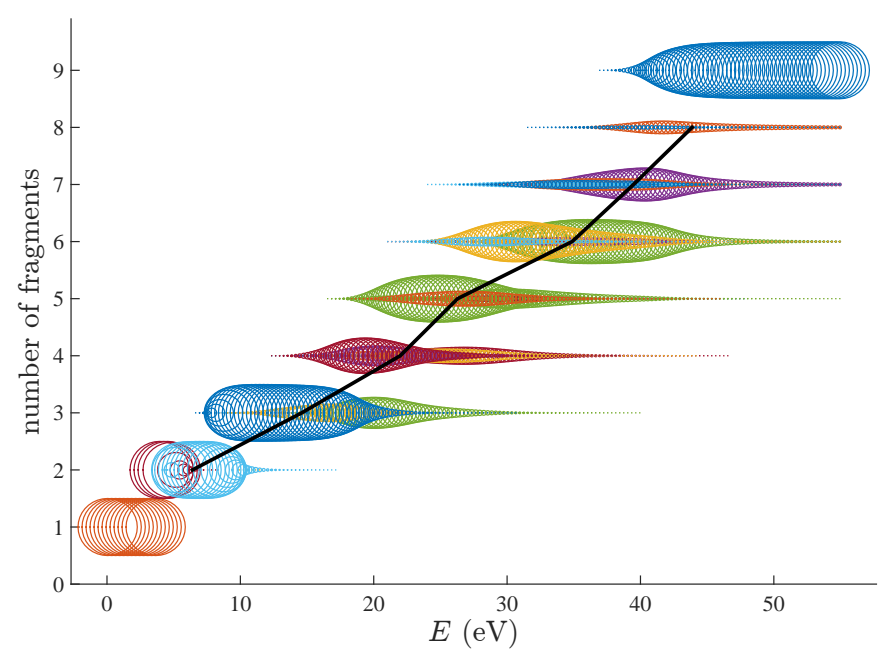

Fig. 5 (Color online) Fragment multiplicity as a function of the parent molecule's excitation energy. The surface of each circle is proportional to the probability of the corresponding fragmentation channel. The channel colors are the same as in figure 3

In the following sections, we check to what extent the results of 
the SMF model depend on the quantum chemistry method used to obtain the molecular properties of the species in the fragmentation channels.

\subsection{Influence of the quantum chemistry methods}

The Gaussian 09 software package 45 was used to calculate all the molecules and radicals predicted to arise from the fragmentation of bonds in propene and in subsequent fragments. In table 1 we specify the meaning of the 2 composite methods ( $5 \zeta$ and G3) and the 2 DFT methods (M06-2X and $++G^{* *}$ ) used to generate the molecular and energetic parameters necessary for the SMF model. Both the $++\mathrm{G}^{* *}$ and $5 \zeta$ methods use B3LYP/6$311++\mathrm{G}^{* *}$ molecular geometries and harmonic vibrational frequencies. The method $5 \zeta$ uses CCSD $(\mathrm{T}) / \mathrm{cc}-\mathrm{pV} 5 \mathrm{Z}$ energies at the minima predicted by $\mathrm{B} 3 \mathrm{LYP} / 6-311++\mathrm{G}^{* *}$ rather than the DFT energies of these minima. The vibrational frequencies were multiplied by an universal scaling factor (0.97) that normally improves agreement with experimental zero-point vibrational energies. This is similar to the philosophy of the G3 composite method where geometries and vibrational frequencies are obtained from less costly quantum chemistry methods while the energies are from higher level methods. The G3 method uses a vibrational scaling factor of 0.893 while M06-2X uses 0.952 .

\begin{tabular}{|c|c|c|}
\hline method name & geometry $/ \bar{v}$ & energy \\
\hline$++G^{* * *}$ & B3LYP $/ 6-311++G^{* *}$ & B3LYP $/ 6-311++G^{* *}$ \\
\hline $5 \zeta$ & B3LYP $/ 6-311++\mathrm{G}^{* * *}$ & CCSD $(T) / c c-p V 5 Z$ \\
\hline G3 & MP2(full)/6-31G* (geom) & QCISD(T)/6-311G(d) + MP4/6-311G(2df,p) \\
\hline & $\mathrm{HF} / 6-31 \mathrm{G}^{*}(\bar{v})$ & MP2(FC) $/ 6-311+\mathrm{G}(3 \mathrm{df}, 2 \mathrm{p})+\Delta E(\mathrm{HLC})$ \\
\hline M06-2X & $\mathrm{M} 06-2 \mathrm{X} / 6-311++\mathrm{G}^{* *}$ & $\mathrm{M} 06-2 \mathrm{X} / 6-311++\mathrm{G}^{* *}$ \\
\hline
\end{tabular}

Table 1 Quantum chemistry methods used in the comparison.

Not all quantum chemistry methods find the same stable species (e.g., a stable species predicted by one method might be a transition state in another method). In our case, M06-2X and G3 could not find the singlet $\mathrm{CH}_{3} \mathrm{CHC}$ and M06-2X could not find the doublet $\mathrm{CH}_{2} \mathrm{CHC}$, while the species were readily found using B3LYP. However, when using the quantum chemistry method for which they were found to be stable, the species have probabilities lower than $10^{-9}$. Despite the SMF model being able to treat arbitrary bond rearrangements that may occur with a fragmentation channel, we only chose to enable 3-carbon ring formations and generation of $\mathrm{H}_{2}$. This choice normally increases the differences between the quantum chemistry methods, since there are potentially more species that may play a role in the fragmentation process and the various quantum chemistry methods may not necessarily find the same species to be stable thus the number of fragmentation channels may vary. Furthermore it was numerically demonstrated $^{32}$ that molecular vibrational frequencies are generally the most influential factor for the fragmentation channel and species probabilities. Therefore, we tested the "convergence" of the SMF results by using vibrational frequencies obtained at 3 different levels of theory (scaled B3LYP/6-311++G**, scaled M06-2X/6-311++ $\mathrm{G}^{* *}$ and scaled $\left.\mathrm{HF} / 6-31 \mathrm{G}^{*}\right)$. In figure 6 we give the geometric mean frequencies for species that converged with all three methods. As can be seen in the figure only a few species, display major deviations in the predicted vibrational fre- quencies. These species, such a cyclic doublet radical CHCC, have very low production rates, thus don't play an important role in the channel yields. On the other hand, it was shown in ${ }^{32}$ that the discrepancies for the more abundant $\mathrm{CH}_{3}$ radical has more influence on the fragmentation yields.

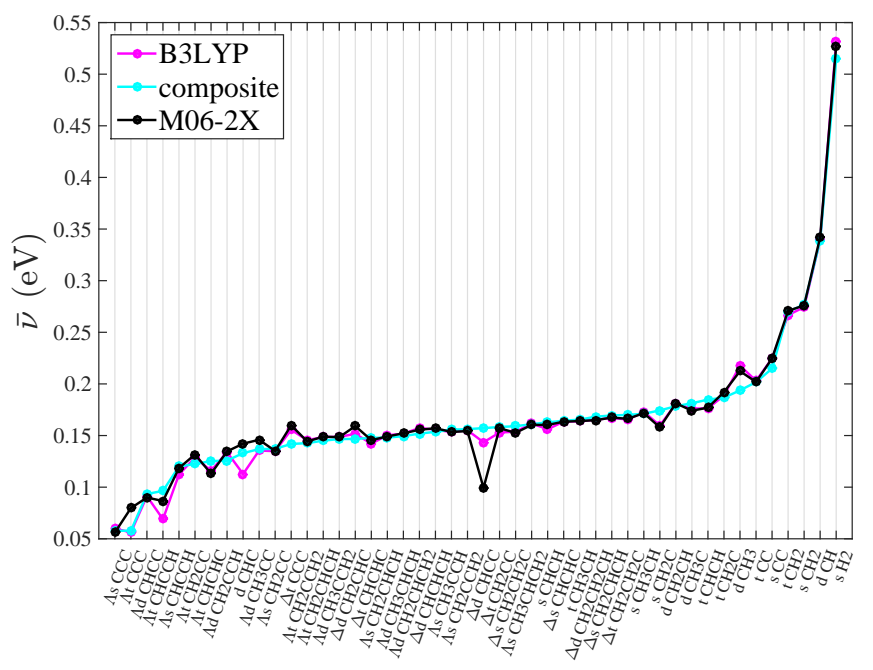

Fig. 6 (Color online) Comparison of the geometric mean vibrational frequencies (in eV) from scaled B3LYP/6-311++ $\mathrm{G}^{* *}$, scaled $\mathrm{HF} / 6-31 \mathrm{G}^{*}$ of the G3 method, and scaled M06-2X/6-311++G**.

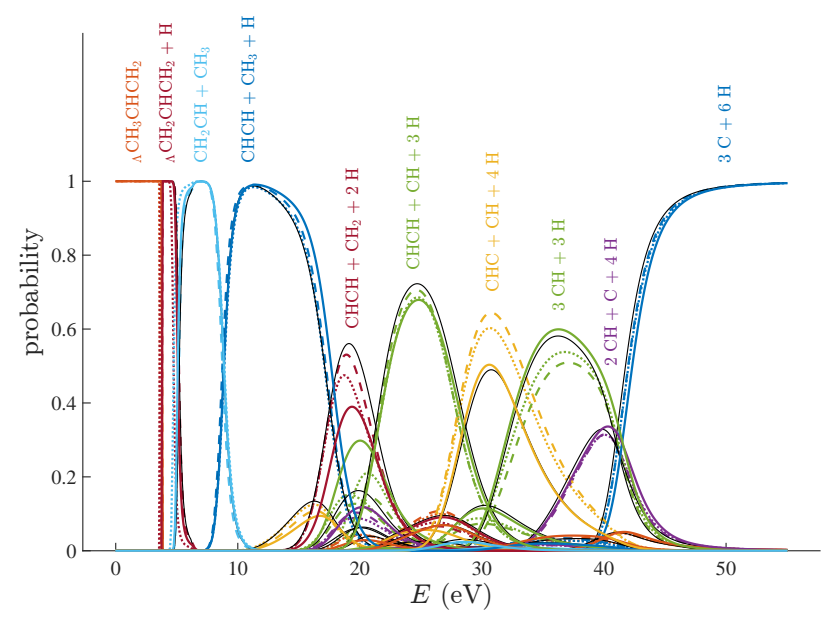

Fig. 7 (Color online) Comparison of the fragmentation channel probabilities for the four methods. Dotted line: $++\mathrm{G}^{* *}$, dashed line: $5 \zeta$, full line: G3, black line: M06-2X.

A comparison of the SMF results using various quantum chemistry methods can be seen in Figs. 7 and 8 . The results are very similar. The best agreement is obtained using the $++\mathrm{G}^{* *}$ and $5 \zeta$ methods. As already shown for propane $\frac{32}{3}$, the G3 composite method shows noticeably larger differences, in particular in the fragmentation species yields. However, the energy ranges are essentially the same. The global agreement between the SMF 


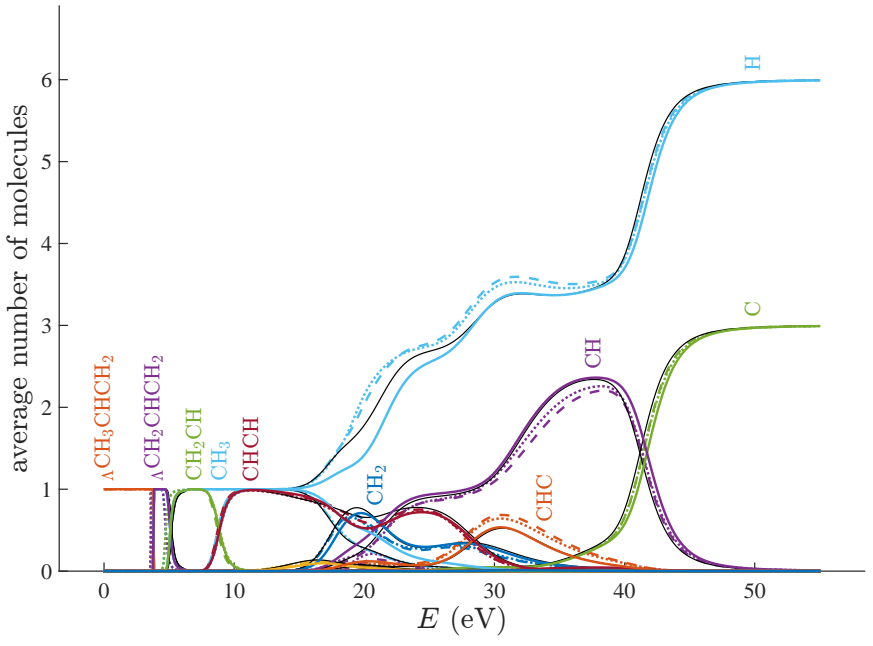

Fig. 8 (Color online) Comparison of the fragment species probabilities for the four methods. Dotted line: $++\mathrm{G}^{\star \star}$, dashed line: $5 \zeta$, full line: $\mathrm{G} 3$, black line: M06-2X.

results based on the four methods can be quantified using the normalised standard deviation:

$$
\sigma_{\mathrm{r}}=\left\langle\sqrt{\frac{\left\langle P^{2}(m, c, e)\right\rangle_{e}}{\langle P(m, c, e)\rangle_{e}^{2}}-1}\right\rangle_{m, c}
$$

where \langle\rangle$_{x}$ stands for the average over parameter $x$, and $P(m, c, e)$ is the channel $c$ probability for method $m$ at energy $e$. For propene, the normalised standard deviations are low: $9.6 \%$ for channel probabilities and $7.5 \%$ for species fragmentation probabilities.

Therefore, with respect to the experimental uncertainties, the differences due to the quantum methods are negligible.

\section{Comparison of SMF predictions to the re- sults from experimental plasma induced propene decay}

\subsection{Fragmentation channel agreement}

The probabilities of the channel generated by the SMF model are shown in figure 9, for excitation energies that are lower than the $\mathrm{N}_{2}^{*}$ metastable states. Two assumptions have been considered: the production of hydrogen molecules from hydrogen atoms initially bound to neighbouring carbons, is either forbidden (dashed line) or allowed (full line). In the latter case, the closure of the three carbon ring is also allowed, but plays a negligible role. The predictions of the model do reproduce the plasma experiment results discussed in Section 2. Indeed, the three reactions (1), (2) and (4) that can be deduced from the experiment, are the same as the fragmentation channels predicted by the SMF model at low excitation energies. When it is assumed that $\mathrm{H}_{2}$ is not produced, then reaction (3) replaces reaction (4) and evidence for its dissociation products $\left(\mathrm{CH}_{2} \mathrm{CH}+\mathrm{CH}_{3}\right)$ would start to appear for excitation energies over $4.7 \mathrm{eV}$. Under the contrary assumption both
Propene

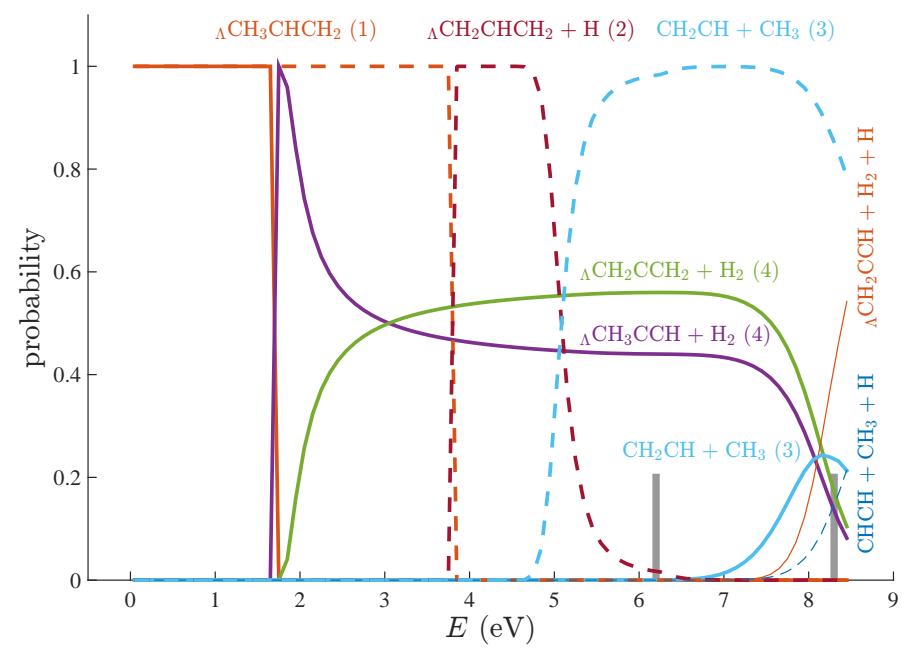

Fig. 9 (Color online) Probability distributions for the sets of channels found in the plasma abatement experiment of propene (heavy lines only, the thin solid lines correspond to the channels which were not seen in the experiment). The full lines correspond to the case when $\mathrm{H}_{2}$ molecules can be generated during the fragmentation and the dashed lines to the case when they cannot be produced. The grey ticks indicate the locations of the $\mathrm{A}^{3} \Sigma_{\mathrm{u}}^{+}$and singlet $\mathrm{N}_{2}^{*}$ metastable state energies.

reaction (4) and reaction (3) would occur, but the later reaction would appear at higher energies $(\geq 6.9 \mathrm{eV})$. In the figure, the sum of channel probabilities are independently normalized to 1 whether $\mathrm{H}_{2}$ production is authorised or not. A global normalization to 1 would entail the knowing of an extra parameter which is not included in the SMF model, namely the probability that the fragmentation of two hydrogen atoms leads to the simultaneous formation of a hydrogen molecule. The experimental results provide an estimate of this parameter. Indeed, the percentage of reaction (4) as measured by the experiment is only $5 \%$, that is about one tenth of each of the other two reactions (1) and (2). As the latter reactions have negligible probabilities when $\mathrm{H}_{2}$ emission is allowed, the $\mathrm{H}_{2}$ coupling parameter has to be of the order of $10 \%$.

Similar agreement between the SMF model and experiment can be noted in figure 10 for three other hydrocarbons: ethene ${ }^{1922431 / 46}$, ethane ${ }^{1924}$ and propane ${ }^{1720}$. In each case the first few fragmentation channels deduced from experiment are the same as those predicted by the SMF model in the low energy regime, combined the with experimental results whether $\mathrm{H}_{2}$ emission is detected or not. Channel probabilities in figure 10 are independently normalized to one for the channels including the formation of $\mathrm{H}_{2}$ and for the channels that exclude the formation of $\mathrm{H}_{2}$. The low energy results of the four hydrocarbons demonstrate the importance of the level of unsaturation of the parent hydrocarbons. The unsaturation reactions have the smallest net reaction enthalpies thus they are the first to appear in the SMF simulations. 

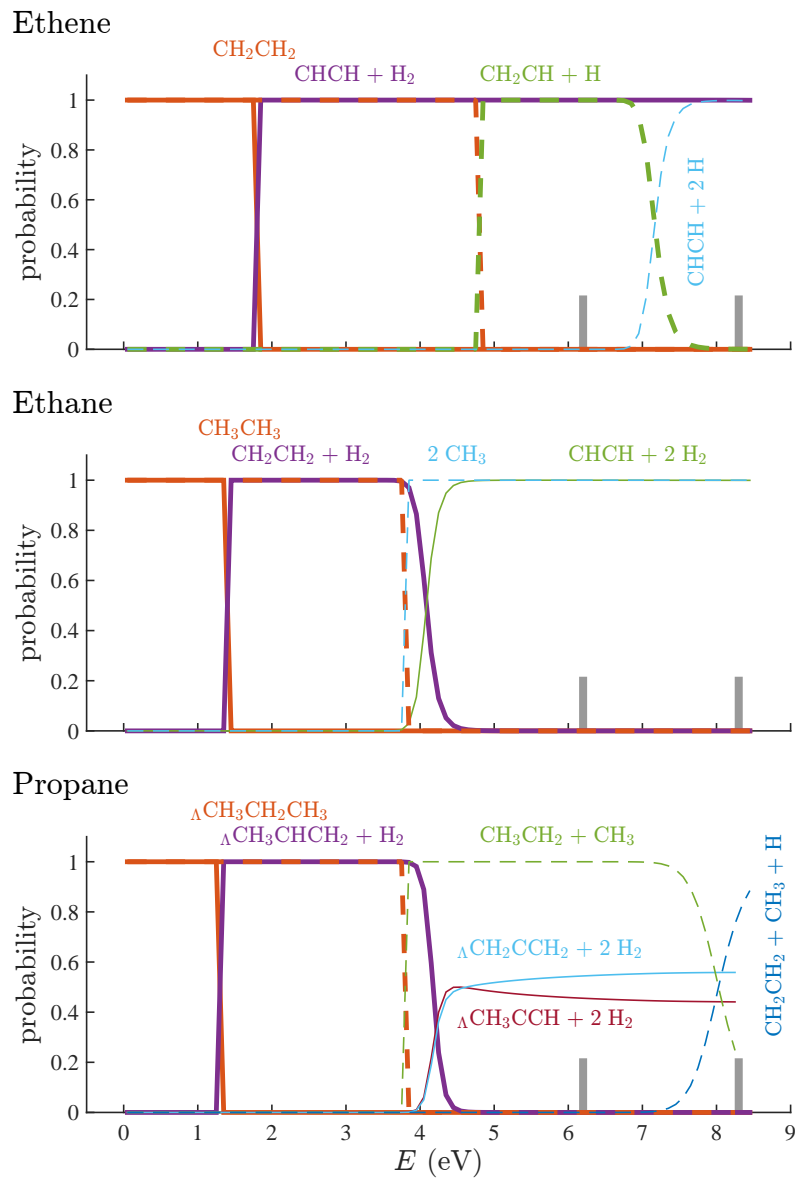

Fig. 10 (Color online). SMF model probabilities for the channels observed in plasma abatement experiments for different hydrocarbons. The same conventions as in the previous figure apply: solid lines are channels where the formation of $\mathrm{H}_{2}$ is allowed and broken lines are channels where $\mathrm{H}_{2}$ formation is not allowed. Thick lines correspond to channels for which experimental evidence was found while thin lines are those which were not seen in the experiments.

\subsection{Consequences on the excitation energy distribution}

During plasma discharge, some of the propene molecules acquired at least part of the excitation energy either by quenching excited nitrogen molecules or by collisions with electrons. These processes result in an excitation energy distribution that is not known in advance, but it can be deduced by comparing the experimental results with the theoretically predicted channel distributions.

The experimentally measured branching ratios suggest that the distribution of energy transferred to the parent molecule is broad and shifted to values lower than the metastable $\mathrm{N}_{2}^{*}$ resonance energies. For propene, since evidence for $\mathrm{CH}_{2} \mathrm{CH}$ was not found in the experiment, the energy distribution has to end below $5 \mathrm{eV}$. Since reaction (2) corresponds to $50 \%$ of the total, one half of the energy distribution integral lies between $3.7 \mathrm{eV}$ and $5 \mathrm{eV}$. Fi- nally, the other half corresponds to non-dissociative excitations of the parent propene, that is excitation energies between 0 and $3.7 \mathrm{eV}$.

The same qualitative conclusions concerning the width and the shift to lower energies with respect to the metastable state energies of the transferred energy distribution can also been drawn from the analysis of the other experimental plasma data. In every case, the predicted distributions for the observed channels populate broadly the excitation energy ranges below the excited levels of the dinitrogen molecule. For ethene, it must start below $4.8 \mathrm{eV}$ to account for non-dissociative reactions and for reactions resulting in emission of $\mathrm{H}_{2}$. In the case of ethane, the distribution must end between $2 \mathrm{eV}$ (to account for $\mathrm{H}_{2}$ production) and $3.8 \mathrm{eV}$ because $\mathrm{CH}_{3}$ was not found. Finally, for propane, the maximum value of the energy distribution has to be between $1.2 \mathrm{eV}$ (to take into account $\mathrm{H}_{2}$ production) and $4 \mathrm{eV}$ since evidence for channels involving the production of $\mathrm{CH}_{3}$ or two $\mathrm{H}_{2}$ molecules was not seen in the experiment.

\section{Conclusion}

The predictions of a statistical physics molecular fragmentation model, SMF, have been compared to the reaction yields deduced from plasma experiments for four hydrocarbons: propene, ethene, ethane and propane. In every case, the agreement between the SMF model and the deduced experimental fragmentation channels is good in the low energy region probed in the experiments. The results confirm the capacity of microcanonical statistical models (i.e. models that do not follow the time evolution of the system but use phase space considerations to evaluate the weights of the exit channels) are able to produce reliable predictions in the relative molecular fragmentation channel yields.

We tested the SMF model's sensitivity of the final fragmentation yields on the structural and energetic properties of all the possible fragment molecules and radicals, by using very different quantum chemistry methods to evaluate these properties. The relative differences between the methods was found to be less than $10 \%$, showing that SMF has a dampening effect on the model differences. This was previously shown for propane ${ }^{32}$ using Linear Discriminant Analysis 47 . It was also shown in ${ }^{32}$ that, compared to other methods, the G3 composite method has a slight tendency to deposit more excitation energy into vibrational modes and into accelerating the separation of the fragments rather than breaking new chemical bonds.

This combined experimental and theoretical study allows one to make conclusions concerning both the experiment and the SMF model. The experiment indicated that the SMF model must include the formation of $\mathrm{H}_{2}$ molecules from the fragmentation of hydrogen atoms on neighbouring carbon atoms. Moreover, the coupling rate for these hydrogen atoms has been estimated to be of the order of $10 \%$ for propene when only a few eV of excitation energy is provided to the propene molecule. On the other hand, the SMF model has permitted the evaluation of the distributions of energies transferred to the four hydrocarbons during the experiments. For all the studied hydrocarbons, this distribution is large, and ends at a value below the metastable $\mathrm{N}_{2}^{*}$ states by about 1 to $2 \mathrm{eV}$. Moreover, the SMF model allowed one to con- 
clude the nature of the $\mathrm{C}_{3} \mathrm{H}_{4}$ products that the experiment could not discriminate: they are a mixture of propadiene and propyne. Cyclopropene is not present in the mixture. Close to the threshold excitation energy $(1.7 \mathrm{eV})$ propyne is the major species, while for excitation energies over $3 \mathrm{eV}$, propadiene represents about $55 \%$ of the mixture.

Complementary experiments for propene have been scheduled for later in 2020. These experiments should evaluate the relative proportions of $\mathrm{CH}_{2} \mathrm{CCH}_{2}$ and $\mathrm{CH}_{3} \mathrm{CCH}$ in order to verify the predictions from the SMF model. Due to the robustness, speed and versatility of the SMF model, it is well adapted to assist in the design and execution of future plasma experiments.

\section{Conflicts of interest}

The authors declare that there are no conflicts of interest.

\section{Appendix}

\subsection{The effects of rearrangements and recombinations}

Rearrangements and recombinations are accounted for in the first step of the SMF model (when all fragmentation channels are listed). For example, when the channel $\mathrm{CH}_{2}+\mathrm{CCH}_{2}+2 \mathrm{H}$ is generated, two other channels are added: $\mathrm{CH}_{3}+\mathrm{CCH}_{2}+\mathrm{H}$ (the capture of an neighboring hydrogen atom by the $\mathrm{CH}_{2}$ ) and $\mathrm{CH}_{2}$ $+\mathrm{CCH}_{2}+\mathrm{H}_{2}$ (hydrogen molecule produced from neighbouring hydrogen atoms). The weights of these two extra channels are calculated using the same protocol as for the first channel. Since SMF is a purely statistical model for fragmentation, recombination events (such as two hydrogen atoms forming a hydrogen molecule or a methylene radical capturing a hydrogen atom) probabilities are missing in the model. In general these probabilities are unknown, but some can be estimated from experimental results or from very extensive dynamical calculations that are not a part of the SMF model.

Figure 11 shows the average number of species, resulting from the fragmentation of a propene molecule, as a function of the excitation energy. In this figure the various rearrangement mechanisms are systematically permitted: closure of the three carbon atom ring, formation of hydrogen molecules from hydrogen atoms of neighbouring carbons, formation of $\mathrm{CH}_{n}$ ( $n$ between 2 and 4) from $\mathrm{CH}_{n-1}$ and hydrogen atoms from neighbouring carbon atoms. This allows one to compare the results of the SMF model with and without recombinations. The results from experiments can also be compared with these two SMF results to possibly distinguish which is the more accurate description. For the fragmentation of propene the following can be concluded. The SMF results are not influenced by the formation of three carbon atom rings and the recombination with hydrogen atoms to form $\mathrm{CH}_{2}$ or $\mathrm{CH}_{3}$, since the channel probabilities are negligible (less than $10^{-8}$ and $10^{-6}$, respectively). Methane formation has a strong influence only in the 6.5-11 eV excitation energy range. Methane is systematically accompanied by a $\mathrm{CH}_{2} \mathrm{C}$ radical. Hydrogen molecule formation has the strongest influence on the SMF results. The main effects of $\mathrm{H}_{2}$ formation are to lower hydrogen atom production in almost the entire excitation energy range (from $3 \mathrm{eV}$ to $45 \mathrm{eV}$ ) and to allow the production of $\mathrm{CH}_{3} \mathrm{CCH}$,
$\mathrm{CH}_{2} \mathrm{CCH}_{2}$, and $\mathrm{CH}_{2} \mathrm{CCH}$ at low excitation energies.

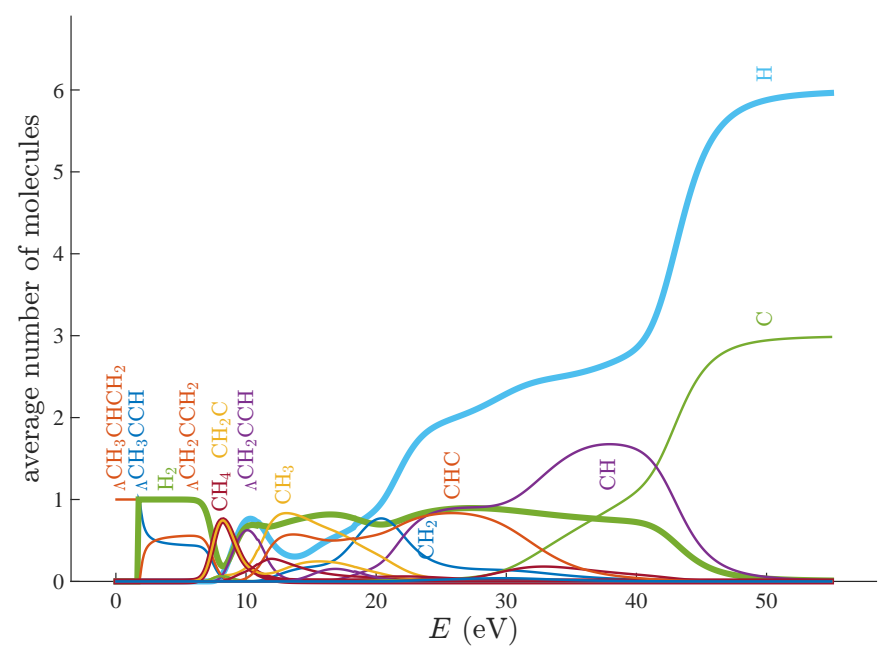

Fig. 11 (Color online) Fragment species probabilities when all possible rearrangement processes in SMF are systematically allowed. This will overestimate channels that normally should have low probability such as those involving the formation of $\mathrm{H}_{2}$.

\subsection{Input parameters for the SMF model}

Table 2 lists the structural and energetic parameters used by the SMF model in the case of the $a b$ initio G3 composite method. These are the only parameters that are currently needed by the SMF model and can be generated by any reliable quantum chemical method.

\section{Notes and references}

1 E. Wigner, Z. Phys. Chem Abt. B, 1932, 19, 203.

2 H. Eyring, J. Chem. Phys., 1935, 3, 107-115.

3 E. Wigner, Trans. Faraday Soc., 1938, 34, 29-41.

4 T. Gierczak, J. Gawlowski and J. Niedzielski, J. Photoch. Photobiol. A, 1988, 43, 1-9.

5 D. L. Osborn, H. Choi, D. H. Mordaunt, R. T. Bise, D. M. Neumark and C. M. Rohlfing, J. Chem. Phys., 1997, 106, 30493066.

6 B. G. Levine and T. J. Martínez, Annu. Rev. Phys. Chem., 2007, 58, 613-634.

7 M. Barbatti, M. Ruckenbauer and H. Lischka, J. Chem. Phys., 2005, 122, 174307.

8 A. Baudic, V. Gros, S. Sauvage, N. Locoge, O. Sanchez, R. Sarda-Estève, C. Kalogridis, J.-E. Petit, N. Bonnaire, D. Baisnée, O. Favez, A. Albinet, J. Sciare and B. Bonsang, Atmos. Chem. Phys., 2016, 16, 11961-11989.

9 M. C. Hsiao, B. T. Merritt, B. M. Penetrante, W. P. H. Vogtlin, George E., R. G. Tonkyn, R. R. Shah and T. M. Orlando, J. Adv. Oxi. Tchnol., 1996, 1, 79-84.

10 R. Dorai and M. J. Kushner, SAE Technical Paper Series, 1999. 


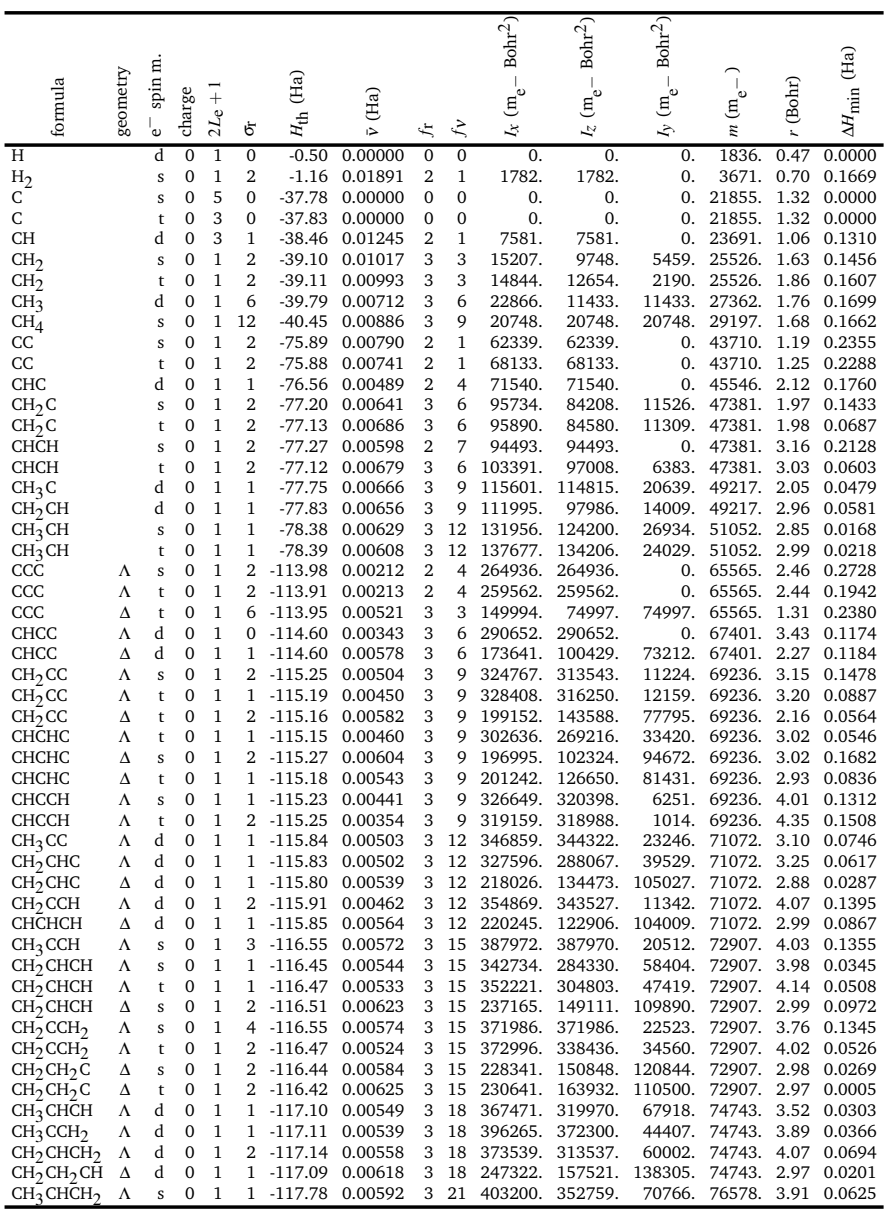

Table 2 Molecular input for the SMF model from the G3 composite method. Letters $\Lambda$ and $\Delta$ stand for linear and cycled three carbon chains and the letters $\mathrm{s}, \mathrm{d}$ and $\mathrm{t}$ stand for singlet, doublet, triplet states. The next columns correspond respectively to the charge, the orbital degeneracy, $\sigma_{\mathrm{r}}$ the geometric degeneracy, $H_{\mathrm{th}}$ the thermal enthalpy, $\bar{v}$ the geometric mean of the frequencies, $f_{\mathrm{r}}$ and $f_{v}$ respectively the number of rotational and vibrational degrees of freedom, $I_{x}, I_{y}, I_{z}$ the principal inertia momenta, $m$ the mass, $r$ the mean radius and $\Delta H_{\min }$ the minimum dissociation energy.
11 I. Orlandini and U. Riedel, Combust. Theory Model., 2001, 5, 447-462.

12 R. Dorai and M. J. Kushner, J. Phys. D, 2003, 36, 1075-1083.

13 N. Marcelino, J. Cernicharo, M. Agúndez, E. Roueff, M. Gerin, J. Martín-Pintado, R. Mauersberger and C. Thum, Astrophys. $J ., ~ 2007,665$, L127-L130.

14 C. A. Nixon, D. E. Jennings, B. Bézard, S. Vinatier, N. A. Teanby, K. Sung, T. M. Ansty, P. G. J. Irwin, N. Gorius, V. Cottini, A. Coustenis and F. M. Flasar, Astrophys. J., 2013, 776, L14.

15 E. Herbst and E. F. van Dishoeck, Annu. Rev. Astron. Astrophys., 2009, 47, 427-480.

16 Z. Lin, D. Talbi, E. Roueff, E. Herbst, N. Wehres, C. A. Cole, Z. Yang, T. P. Snow and V. M. Bierbaum, Astrophys. J., 2013, 765, 80.

17 S. Pasquiers, N. Blin-Simiand and L. Magne, Plasma Physics and Controlled Fusion, 2013, 55, 124023.

18 B. Lacour, V. Puech and S. Pasquiers, Recent Res. Develop. Appl. Phys., 2003, 6, 149.

19 L. Magne, S. Pasquiers, K. Gadonna, P. Jeanney, N. BlinSimiand, F. Jorand and C. Postel, J. Phys. D, 2009, 42, 165203.

20 N. Moreau, S. Pasquiers, N. Blin-Simiand, L. Magne, F. Jorand, C. Postel and J.-R. Vacher, J. Phys. D, 2010, 43, 285201.

21 W. Faider, S. Pasquiers, N. Blin-Simiand and L. Magne, J. Phys. D, 2013, 46, 105202.

22 L. Magne, N. Blin-Simiand, K. Gadonna, P. Jeanney, F. Jorand, S. Pasquiers and C. Postel, Eur. Phys. J.-Appl. Phys., 2009, 47, 22816.

23 S. Pasquiers, N. Blin-Simiand and L. Magne, Eur. Phys. J.-Appl. Phys., 2016, 75, 24703.

24 J. T. Herron, J. Phys. Chem. Ref. Data, 1999, 28, 1453-1483.

25 J. A. Meyer, D. H. Klosterboer and D. W. Setser, J. Chem. Phys., 1971, 55, 2084-2091.

26 E. Bohmer and W. Hack, Z. Phys. Chem., 1991, 170, 15.

27 W. G. Clark and D. W. Setser, J. Phys. Chem., 1980, 84, 22252233.

28 M. F. Golde, Int. J. Chem. Kinet., 1988, 20, 75-92.

29 W. Tao, M. F. Golde, G. H. Ho and A. M. Moyle, J. Chem. Phys., 1987, 87, 1045-1053.

30 M. F. Golde, G. H. Ho, W. Tao and J. M. Thomas, J. Phys. Chem., 1989, 93, 1112-1118.

31 H. Umemoto, J. Chem. Phys., 2007, 127, 014304.

32 P. Désesquelles, N.-T. Van-Oanh, S. Thomas and D. Domin, Phys. Chem. Chem. Phys., 2020, 22, 3160-3172.

33 L. Xu, W. Li, P. Désesquelles, N.-T. Van-Oanh, S. Thomas and J. Yang, J. Phys. Chem. A, 2019, 123, 933-942.

34 S. Díaz-Tendero, G. Sánchez, M. Alcamí, F. Martín, P.-A. Hervieux, M. Chabot, G. Martinet, P. Désesquelles, F. Mezdari, K. Wohrer-Béroff, S. D. Negra, H. Hamrita, A. LePadellec and L. Montagnon, Int. J. Mass Spectrom., 2006, 252, 126 132.

35 G. Sun, M. Lucas, Y. Song, J. Zhang, C. Brazier, P. L. Houston and J. M. Bowman, J. Phys. Chem. A, 2019, 123, 9957-9965. 
36 Y.-C. Han, B. C. Shepler and J. M. Bowman, J. Phys. Chem. Letters, 2011, 2, 1715-1719.

37 N.-T. Van-Oanh, P. Parneix and P. Bréchignac, J. Phys. Chem. A, 2002, 106, 10144-10151.

38 N.-T. Van-Oanh, C. Falvo, F. Calvo, D. Lauvergnat, M. Basire, M.-P. Gaigeot and P. Parneix, Phys. Chem. Chem. Phys., 2012, 14, 2381-2390.

39 F. Calvo, N.-T. Van-Oanh, P. Parneix and C. Falvo, Phys. Chem. Chem. Phys., 2012, 14, 10503.

40 A. Simon, M. Rapacioli, G. Rouaut, G. Trinquier and F. X. Gadéa, Philos. Trans. R. Soc. A, 2017, 375, 20160195.

41 L. Beaulieu, T. Lefort, K. Kwiatkowski, W.-c. Hsi, G. Wang, D. S. Bracken, E. Cornell, D. S. Ginger, K. B. Morley, V. E. Viola, F. Gimeno-Nogues, R. Laforest, E. Martin, E. Ramakrishnan, D. Rowland, A. Ruangma, E. Winchester, S. J. Yennello, R. G. Korteling, L. Pienkowski, H. Breuer, B. Back, S. Gushue, L. P. Remsberg, M. J. Huang, W. G. Lynch, M. B. Tsang and H. Xi, Phys. Rev. C, 2001, 64, 064604.

42 P. Lautesse, L. Nalpas, R. Dayras, M. F. Rivet, M. Pârlog, E. Bisquer, B. Borderie, R. Bougault, P. Buchet, J. L. Charvet, A. Chbihi, M. Colonna, A. Demeyer, P. Désesquelles, J. D. Frankland, E. Galichet, E. Gerlic, D. C. R. Guinet, R. Legrain, N. Le Neindre, O. Lopez, L. Manduci, A. M. Maskay, G. Noguère, E. Rosato, R. Roy, C. Schmitt, M. Stern, B. Tamain, E. Vient, M. Vigilante, C. Volant, J. P. Wieleczko and I. Collaboration, The European Physical Journal A Hadrons and Nuclei, 2006, 27, 349-357.

43 D. T. Nga, PhD thesis, Université Paris-Sud, 2011.

44 P. Désesquelles, Phys. Lett. B, 2011, 698, $284-287$.

45 M. J. Frisch, G. W. Trucks, H. B. Schlegel, G. E. Scuseria, M. A. Robb, J. R. Cheeseman, G. Scalmani, V. Barone, B. Mennucci, G. A. Petersson, H. Nakatsuji, M. Caricato, X. Li, H. P. Hratchian, A. F. Izmaylov, J. Bloino, G. Zheng, J. L. Sonnenberg, M. Hada, M. Ehara, K. Toyota, R. Fukuda, J. Hasegawa, M. Ishida, T. Nakajima, Y. Honda, O. Kitao, H. Nakai, T. Vreven, J. A. Montgomery, Jr., J. E. Peralta, F. Ogliaro, M. Bearpark, J. J. Heyd, E. Brothers, K. N. Kudin, V. N. Staroverov, R. Kobayashi, J. Normand, K. Raghavachari, A. Rendell, J. C. Burant, S. S. Iyengar, J. Tomasi, M. Cossi, N. Rega, J. M. Millam, M. Klene, J. E. Knox, J. B. Cross, V. Bakken, C. Adamo, J. Jaramillo, R. Gomperts, R. E. Stratmann, O. Yazyev, A. J. Austin, R. Cammi, C. Pomelli, J. W. Ochterski, R. L. Martin, K. Morokuma, V. G. Zakrzewski, G. A. Voth, P. Salvador, J. J. Dannenberg, S. Dapprich, A. D. Daniels, O. Farkas, J. B. Foresman, J. V. Ortiz, J. Cioslowski and D. J. Fox, Bréch 09 Revision A.02, Gaussian Inc. Wallingford CT 2016.

46 F. Fresnet, G. Baravian, L. Magne, S. Pasquiers, C. Postel, V. Puech and A. Rousseau, Appl. Phys. Lett., 2000, 77, 41184120.

47 P. Désesquelles, Ann. Phys., 1995, 20, 1-45. 